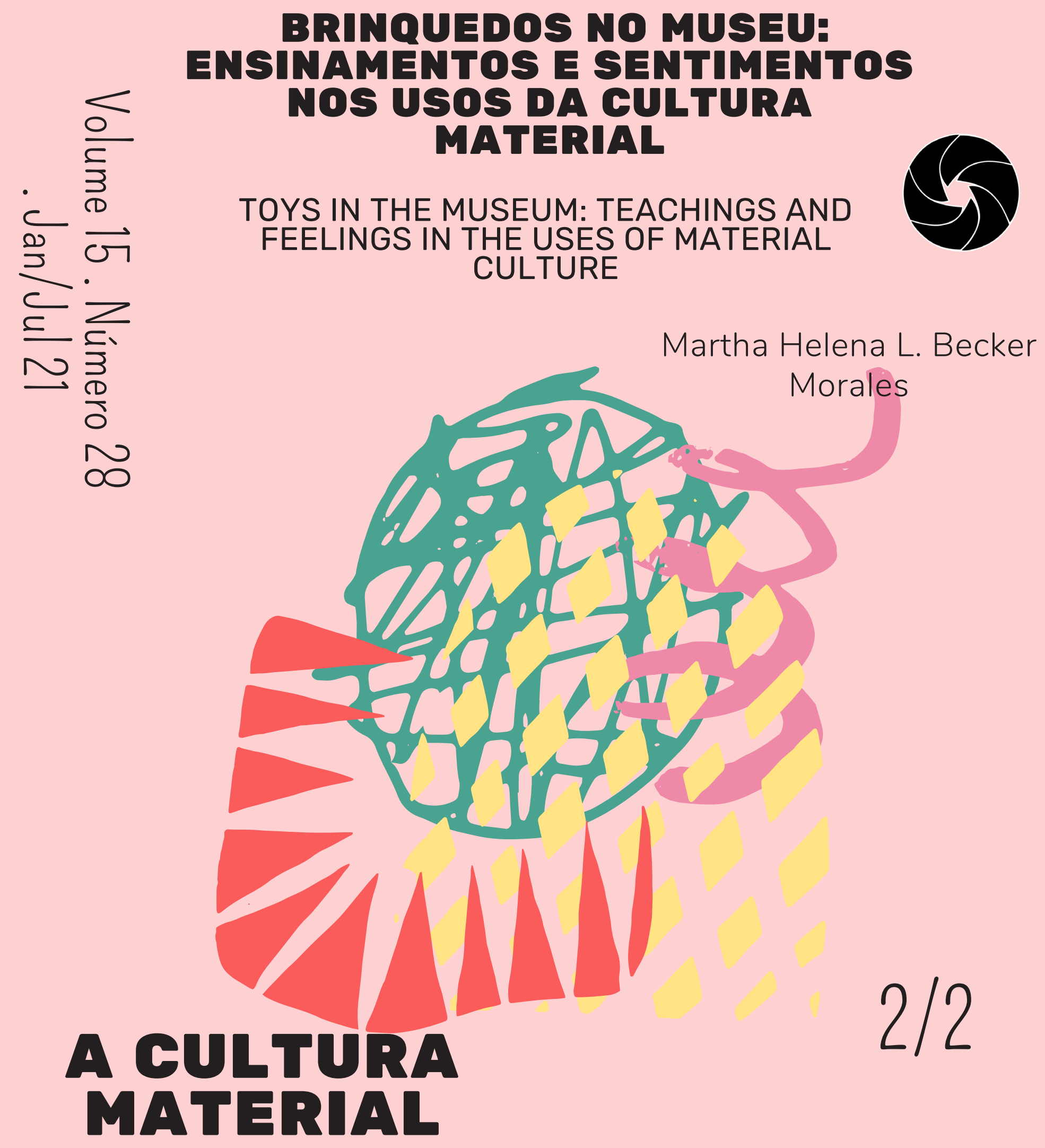

objetos, imagens e representacōes
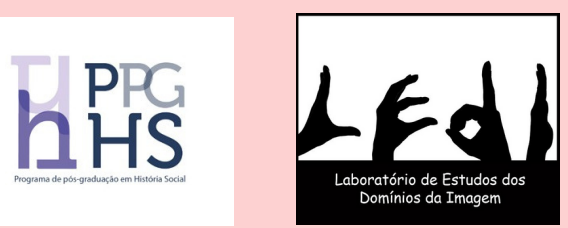

Organização:

Prof ${ }^{a} \mathrm{Dr}^{a}$ Cláudia Eliane

Parreiras Marques Martinez 


\section{BRINQUEDOS NO MUSEU: ENSINAMENTOS E SENTIMENTOS NOS USOS DA CULTURA MATERIAL}

\section{TOYS AT THE MUSEUM: TEACHINGS AND FEELINGS IN THE USE OF THE MATERIAL CULTURE}

\author{
Martha Helena L. Becker Morales ${ }^{1}$
}

\begin{abstract}
Resumo: Este artigo apresenta os resultados de uma pesquisa realizada em torno de um conjunto de brinquedos doados ao Museu Paranaense entre 2014 e 2015. Três ênfases recaem sobre a análise da cultura material: em primeiro lugar, a agência das doadoras que, antes de repassá-los à instituição, classifica e seleciona os objetos conforme suas expectativas de consolidação da memória. Em segundo lugar, o museu e a transformação de experiências particulares em um discurso representativo de coletividades. Por fim, há o destaque às muitas possibilidades interpretativas que o novo acervo musealizado permite, direcionando olhares de pesquisador e visitante - duas categorias presentes no cotidiano do museu. Em termos práticos, o artigo problematiza os brinquedos em questão como pedagogias culturais materiais que agem na intersecção do consumo pretendido no início do século XX com o potencial explicativo no contexto museológico do início do século XXI. Assim, diferentes ensinamentos, sentimentos e usos são abordados para delinear práticas de poder e construção de papéis específicos a serem viabilizados pela cultura material.
\end{abstract}

Palavras-chave: Cultura material; Brinquedo; Museu; Memória.

\begin{abstract}
This article presents the results of a research conducted on a collection of toys donated to the Paranaense Museum over a period of two years - 2014 and 2015. There are three main focuses: firstly, the donors' agency who, prior to giving the objects to the institution, classified, and selected what would be donated according to their own expectations of the memories to be preserved. Then, the museum itself and the turning of private experiences into collectively shared narratives. Finally, the article brings to light many possible interpretations of this newly added collection, offering perspectives to researchers and visitors - two groups present in day-to-day museum activities. In practical terms, the discussion poses these toys as cultural material pedagogies that work within the intersection of the intended usage during the first half of the 20th century and its explanatory potential when incorporated by the museum at the beginning of the 21 st century. Thereby, different teachings, feelings and uses can be thought out to better understand the practice of power and the structuring of specific roles made viable by the material culture.
\end{abstract}

Keywords: Material Culture; Toy; Museum; Memory.
1 Doutora em História pela Universidade Federal do Paraná, Curitiba-PR, com estágio de pós-doutoramento concluído pelo Programa de Pós-Graduação em História da mesma instituição em 2018. Atua como professora de Ensino Fundamental e Médio na rede privada de Curitiba, Paraná. Contato: mhlbecker@gmail. com. ORCID iD: 00000003-0127-1876 


\section{INTRODUÇÃO: SOBRE BRINCAR DE CASINHA NO MUSEU}

Entre os anos de 2014 e 2016 foram colocadas em prática algumas propostas de ressignificação do acervo material do Museu Paranaense (doravante MP), instituição localizada na cidade de Curitiba, Paraná, por um viés interdisciplinar dialógico que buscou a compreensão da cultura material como um conjunto artefatual que cria e é criado pela experiência humana, e cujos usos em diferentes contextos podem estabelecer uma série de ensinamentos e sentimentos. O presente artigo expõe os resultados dessa experiência, desenvolvida em pós-doutoramento, com base em discussões bibliográficas, análise de fontes materiais e experiências museológicas. As atividades narradas estiveram pautadas pela problematização e contraposição de diferentes sentimentos construídos nas relações com a cultura material, considerando especialmente sua incorporação em acervos de museus históricos, delineando práticas de poder e construções de papéis de gênero nesse ínterim.

A instituição em questão tem um acervo com cerca de 400 mil itens, divididos em coleções que, embora se encontrem sob a guarda do setor de Museologia, são seccionadas em conformidade com os atuais setores técnicos - Antropologia, Arqueologia e História. Há uma enorme diversidade de tipologias materiais, produto de doações espontâneas, compra de acervos particulares, coletas científicas e heranças de pesquisadores e outros personagens que viveram especialmente no Paraná. Embora houvesse, nos idos do século XIX, uma preferência por exemplares de ciências naturais, botânica, mineralogia, zoologia, numismática, objetos exóticos e curiosidades de personagens históricos (CARNEIRO, 2001), hoje o Museu Paranaense identifica-se como "o mais importante museu histórico do Paraná” (SEEC, 2006, p. 8), ou seja, há uma tendência à construção de narrativas ditas históricas, ainda que o ecletismo do acervo permite inúmeras abordagens expositivas.

O recorte deu-se sobre coleções recém-incorporadas ao museu, caracterizadas como 'brinquedos' tanto pelas doadoras quanto pela equipe técnica que as acolheu. Quase de imediato, foram associadas ao acervo dito 'histórico', uma problemática em si mesma, ainda que seja prática recorrente nas ações institucionais internas (cf. MORALES, 2015b). Entre os muitos objetos, ademais, desdobrou-se outra subcategoria - foram apartados aqueles que faziam referência à 'brincadeira de casinha', em geral utensílios de cozinha e mesa. Diante desta escolha, o brinquedo foi entendido como projeto adulto de fixação de papéis, como repositório de memórias e, finalmente, como narrativa do passado musealizado.

A pesquisa é muito devedora do Grupo de Trabalho em Cultura Material e Infância, instituído no Museu Paranaense em 2015, formado por técnicos da própria insti- 
tuição e universitários de Curitiba, em caráter voluntário. Diretamente ligada à doação ao longo de 2014 de dois conjuntos materiais com abundância de brinquedos, a criação do grupo de trabalho teve como intuito explorar em profundidade o processo de inserção destes objetos nas atividades expositivas, educativas e sociais do MP (MORALES, 2015a). Após o fim da função primária desses brinquedos, produzidos, sobretudo, na primeira metade do século XX, haviam sido preservados no seio familiar como objetos de decoração, de afeto, signo de memórias, pequenas curiosidades. Uma vez transmitidos à guarda do museu, adquiriram a condição de 'bens inalienáveis', conforme afirma Gonçalves (2005), cujo caráter mercadológico foi para sempre substituído pela função museológica de assegurar continuidade no tempo e no espaço, de simbolizar memórias coletivas e narrar histórias de técnica, de moda, de projetos do passado.

Entre as muitas doações que o museu recebe anualmente, desde sua fundação em 1876, chamou à atenção nestes conjuntos a quantidade de utensílios domésticos em escala reduzida, grande maioria em cerâmica branca, exibindo marcas de fabricação estrangeira e nacional, inclusive curitibana. Como parte do cenário da brincadeira de casinha, as pequenas louças têm um favorecimento de sua longevidade no uso amplamente disseminado como decoração de residências (MAJEWSKI; O’BRIEN, 1987), o que enfim potencializa suas chances de chegarem intactas ao museu.

De fato, poderia ser questionada a classificação de tais objetos como brinquedos, uma vez que podem ser encontrados com facilidade em lojas especializadas em bibelôs, por exemplo. Todavia, um dos questionamentos centrais neste trabalho é justamente a significação construída ao redor da cultura material que ultrapassa em muito os usos potenciais imaginados pelo fabricante e, muitas vezes, atribuem papéis considerados contraditórios ao longo da vida social de um objeto.

Em termos gerais, o objetivo é problematizar e contrapor os diferentes sentimentos construídos nas relações com a cultura material desde a sua fabricação até a incorporação ao acervo do museu, delineando práticas de poder e construções de papéis de gênero. Logo, são três os desdobramentos: em primeiro lugar, é fundamental compreender a pedagogia cultural material que se conforma por meio do brinquedo como um projeto adulto de fixação dos papéis de gênero. Em segundo, é importante conhecer os meandros simbólicos da ressignificação da cultura material ao tornar-se repositório de memórias. Finalmente, identificar o lugar dos brinquedos no museu e sua inserção nas narrativas históricas musealizadas para concluir o percurso investigativo.

\section{QUADRO TEÓRICO-METODOLÓGICO: CAMINHOS DA INVESTIGAÇÃO}

O uso da materialidade como objeto de pesquisa é o que orientou as escolhas teóri- 
cas e metodológicas neste trabalho. Privilegiada em estudos de Arqueologia (GARRAFFONI, 2008), a cultura material tem recebido um tratamento igualmente interessante na Antropologia dos Objetos (MILLER, 2004) e na História (CARVALHO, 2008), superada a noção que a relegava a condições subalternas à documentação escrita. Ainda assim, Carvalho (2003, p. 306) acentua que "o potencial do universo físico como documento aumenta conforme aumenta a possibilidade de contextualizá-lo", seja por meio do acesso a registros iconográficos, a reportagens, depoimentos ou propagandas.

O presente recorte configura um estudo de caso no qual uma categoria material, a louça, é analisada com destaque. Fortemente associada ao período de florescimento e desenvolvimento das indústrias, é muito utilizada em pesquisas de tônica socioeconômica, comportamento de consumo e status individual ou familiar. Dessa maneira, há uma vasta gama de autores disponíveis para orientar o estudo específico de formatos, tamanhos, técnicas decorativas, cadeia produtiva e dados de uso e reuso em diferentes contextos (cf. MORALES, 2014). Além disso, por se tratar de objetos em um museu, é fundamental explorar na medida do possível sua biografia cultural, ou seja, a história de como foram transformados em "ícones legitimadores de ideias, valores e identidades" (GONÇALVES, 2005, p. 11). Assim, um objeto incorporado ao acervo seguiu uma trajetória prévia, foi produzido e consumido de alguma forma, para ser então extraído do cotidiano e transformado em algo que se deseja preservar de maneira perpétua, se não pública. Muitas dessas informações se encontram nos documentos associados à doação, ainda que filtradas pelo olhar do doador-depoente - o que, de maneira nenhuma, empobrece o registro de ideias, memórias e sentimentos acerca da cultura material.

Uma vez reconhecida sua capacidade de reforçar ideologias, de formar estruturas familiares e, inclusive, de atuar no corpo (COCHRAN; BEAUDRY, 2008), a cultura material passa a ser vista tanto como matéria quanto metáfora. Ou seja, estudar a cultura material é, de maneira ampla, investigar a relação entre pessoas e objetos independentemente do tempo e do espaço, reconhecendo o papel ativo dos objetos na vida humana, bem como aceitando que as situações analisadas não se encaixam em padrões ou esquemas classificatórios rígidos.

O fato é que objetos, com suas mais variadas formas e aplicações, podem ser testemunhos eloquentes para a interpelação do passado mesmo em situações nas quais não se dispõe de textos que expliquem sua função ou produção, pois

\footnotetext{
Não apenas demarcam ou expressam (...) posições e identidades, mas na verdade, enquanto parte de um sistema de símbolos que é condição da vida social, organizam ou constituem o modo pelo qual os indivíduos e os grupos sociais experimentam subjetivamente suas identidades e status (GONÇALVES, 2005, p. 8).
}

Sendo assim, o trabalho com os brinquedos os admite enquanto discursos em si, 
mas propõe fazer uso da disponibilidade de outras tipologias documentais que proporcionam uma compreensão mais ampla dos significados que podem ter recebido e modificado ao longo do tempo. Nesse sentido, trata-se de pensá-los com relação à discursividade em torno dos ideais de civilidade e etiqueta que estabeleceram as regras para o uso da materialidade criada para os rituais de sociabilidade no ambiente privado da virada do século XIX para o XX; bem como vinculá-los ao projeto museológico do começo dos anos 2000 que desponta em um contexto de diversificação das narrativas acerca do passado, pensando em sujeitos plurais, releituras críticas, desnaturalização de conceitos. Para estes propósitos, é fundamental a contribuição de Albuquerque Jr. (2007, p. 69), para quem as inovações historiográficas estão "nas novas conexões que consigamos estabelecer entre as séries de eventos e documentos que conhecemos".

Desse modo, o resultado buscado não é um perfeito retrato dos comportamentos esperados de meninas de certa classe social na Curitiba da primeira metade do século $\mathrm{XX}$, mas os contornos de um projeto disciplinador que, criando e se apropriando do discurso das boas maneiras, empreende formas de controle sobre corpos femininos ainda em formação. Assim, a problemática tangencia a princípio uma tríade de conceitos formada pela infância sujeitada pela etiqueta a papéis definidos de gênero.

A infância é um conceito que emerge como tema multidisciplinar de estudos nos últimos anos (CASTRO, 2007) além de ser entendida como um fenômeno contextual pela maioria dos pesquisadores (vide ARIÈS, 1978). Consolidada no período oitocentista, a noção de infância vem atrelada a discussões sobre biopolítica e disciplina e, no que diz respeito à cultura material formada pelos brinquedos, compartilha laços com o avanço do mercado consumidor:

\footnotetext{
A criança esteve durante toda a história na dependência da concepção adulta sobre seus papéis e suas necessidades. Quando a criança passou a ser entendida como ser em formação, porém pensante e atuante, passaram a existir produtos específicos para o público infantil embutidos de interesses políticos e sociais (FRISO et al, 2014, p. 1).
}

Contudo, essa dependência e a correlação com os adultos responsáveis não podem desconsiderar a possibilidade da resistência por parte das crianças quando submetidas a regimes fixos de conduta e disciplina. Pereira (2009, p. 6) destaca a transgressão do conteúdo do brinquedo pelas crianças que "utilizam-no de forma não pensada pelo seu fabricante, encantam-se com detalhes que pareciam secundários, inventam novos usos, os destroem a fim de encontrar sua alma”, ou seja, por mais categorizado que se apresente, a imaginação infantil pode surpreender. É uma observação importante para esclarecer que se trata de uma intenção, um projeto político de formatação de indivíduos, mas há sempre espaço para o desvio e a transgressão.

Em termos de etiqueta, trata-se também da análise de um ideal, um projeto que age 
como produtor da readequação dos espaços e dos relacionamentos. Conforme Bezerra,

Além dos objetos que foram incorporados ao cotidiano de inúmeras famílias pelo mundo, os rituais que os seguem também foram incorporados. A forma de se vestir, de comer, de se sentar passou a fazer parte da rotina dos quais desejaram se aproximar da sociedade europeia, modelo de civilidade e progresso. (BEZERRA, 2014a, p. 12)

Logo, a questão da etiqueta remete à ritualização dos comportamentos e, neste caso, das ações que envolvem a comensalidade, uma vez que a amostra selecionada diz respeito, sobretudo, a miniaturas de utensílios de cozinha e mesa. O conhecimento das atitudes corretas à mesa, o domínio sobre as regras, denotavam o pertencimento social - como no exemplo do jantar de finais do século XIX, tornado uma cerimônia de "negociações sociais, alianças e relações de reciprocidade" marcada por "restrições e obrigações relacionadas a expressões naturais do corpo, movimentos exigidos no uso do equipamento de mesa e na relação com os convidados e anfitriões" (TOCCHETTO, 2010, p. 189). O ritual do chá, por sua vez, configurar-se-ia na demonstração de status, por meio da aparelhagem sofisticada, mas também em uma cerimônia de influência e cuidado matriarcal - Beddoes (2014, p. 29) salienta que o papel da mulher aqui "era apreendido durante a infância, por meio da observação e da brincadeira”, referindo-se aos pequenos jogos de chá que estimulavam a prática da etiqueta adulta entre crianças.

Aliás, é dessa maneira que os caminhos de análise levam à problemática dos papéis de gênero, pois, de acordo com Felipe (2000, p. 119), "educadas para servir e agradar sempre, em especial aos homens, as mulheres deveriam cultivar a simplicidade e o recato", ensinamentos estes obtidos por diversos meios, entre eles a leitura de livros de boas maneiras, revistas de moda e comportamento, ou outros guias prescritores do seu lugar no mundo. Quando selecionadas as miniaturas de utensílios em meio aos brinquedos doados houve pouca dúvida quanto a sua associação ao universo das meninas, pois

\footnotetext{
Objetos se tornam emblematicamente sexualizados. Tal imanência, no entanto, deve ser entendida como um resultado da prática social, cotidianamente reiterada pela prática social, momento em que se atribui o gênero aos objetos (CARVALHO, 2008, p. 44).
}

Consequentemente, é preciso ponderar acerca do questionamento proposto por Sudjic (2010): as propriedades dos materiais são intrínsecas ou seus significados são adquiridos pela repetição constante, pela familiaridade e pela convenção? Afinal, assim como a infância, os papéis adequados aos homens ou às mulheres são criação inteiramente social e contextual (SCOTT, 1995). Dessa forma, a questão não isenta o próprio museu em sua classificação dos brinquedos como 'de meninas' ou 'de meninos' - o que conduz a análise para o novo eixo de interesse, ainda sobre uma mesma cultura material, mas deslocando o olhar para outro contexto espacial e temporal.

Enfim, com a entrada no século XXI, as xícaras e pratos em miniatura chegam ao 
museu, por meio da intenção de preservar algo a que a família não atribui o mesmo valor que no passado. Por parte das doadoras, estes objetos ainda merecem deferência, pois, segundo Sudjic (2010, p. 21), colecionar "pode ser também uma tentativa de desafiar a ameaça da mortalidade", preservando elementos de uma época da vida permeada por lembranças positivas, sejam elas precisas ou exageradas. O MP apresenta a chance de infundir sobrevida nestas memórias, visto que colecionadores costumam ver a si mesmos como 'salvadores' de objetos e mundos desaparecidos, o que faz do recolhimento por parte do museu uma legitimação do tempo investido em sua coleção (HECHT, 2001). O caráter permanente e inalienável do acervo museológico parece o caminho ideal para perpetuar esse salvamento do passado.

O hábito do colecionismo traz ao museu a oportunidade de contatar um universo material que talvez não exista mais, embora o faça por meio de recortes e seleções que atendam em primeiro lugar ao interesse do colecionador. Este contato demonstra a resiliência dos objetos em comparação aos corpos ou a outros objetos coevos, como registros presentes do passado (WEISMANTEL, 2011), e, simultaneamente, remete às circunstâncias atuais nas quais se encontram, realocados e ressignificados.

No campo de ação do museu, são introduzidas novas questões de escolha, destaque e ausência que, apesar de dependerem da seleção prévia dos objetos conduzidos pelos sujeitos para a doação, serão operacionalizados pelo corpo técnico que define o que expor e o que guardar. Todavia, é necessário reconhecer esses recortes que se formam e se reformam atrelando ao acervo institucionalizado sua documentação de origem, ou seja,

Entender os critérios que permitiram à doadora decidir entre o que ficava e o que deveria ir para o museu parece fundamental. Assim, trata-se igualmente de documentar a história social dos objetos e não apenas as informações que o doador entende que devam ser consideradas (CARVALHO, 2011, p. 463).

Dessa forma, são abarcados os ensinamentos e os sentimentos implicados nos diversos usos de um mesmo conjunto material. Em primeira instância, os objetos de consumo exibem um perfil de utilidade, um investimento na educação de meninas das quais se espera um comportamento adequado ao meio social no qual vivem. Quase um século mais tarde, a serventia prática dá lugar ao agradável, com a materialização de memórias verificada nos objetos fora do circuito cotidiano, ressignificados como símbolos do passado, da família, da infância. Não são posições contraditórias, mas sintomas da conjuntura que, constantemente, dá sentido(s) à cultura material.

\section{ENSINAMENTOS: UMA PEDAGOGIA CULTURAL MATERIAL}

Sob a classificação de 'útil e agradável', a edição 150 da Revista Illustrada veiculada no Rio de Janeiro do final do século XIX divulgou a publicação do livro Noções da Vida 
Doméstica, de Felix Ferreira, como uma ferramenta importante na educação do sexo feminino - defeituosa, na opinião do periódico. O objetivo último do livro, informa, seria "educar a moça para o salão e prepará-la ao mesmo tempo para dirigir o resto da casa" (REVISTA, 1879, p. 2).

Conforme Sampaio (2013, p. 297), manuais deste tipo "emergem da necessidade de sistematizar os comportamentos advinda de uma nova rede de sociabilidade introduzida pela sociedade do século XIX", experimentando um boom no mercado editorial impulsionado ainda mais pela urbanização e alfabetização crescentes do século XX. Em termos historiográficos, por influência da difusão de ideias como a do processo civilizador de Norbert Elias e da disciplina dos corpos de Michel Foucault, a temática da etiqueta prosperou em análises como a de Tomé (2013), que vê nos manuais uma forma de pedagogia cultural.

A autora aponta que manuais ofereciam conselhos sobre refinamento e polidez, com a finalidade de governo do lar por boas donas de casa, mães e esposas, sem negligenciar o cuidado com a própria aparência. Tal proposta visava a "conservação e manutenção da ordem social, na formação de hábitos de recato e civilidade” (TOMÉ, 2013, p. 66), algo que remonta a um contexto histórico ocidental específico. Verificado no mundo anglo-saxão vitoriano, o chamado culto da domesticidade investia na educação formal das meninas com o intuito de prepará-las para o futuro doméstico, contudo, Joan Scott (1995) alertou que houve um momento em que os estudos de gênero abordaram essa ideologia vitoriana como algo inconteste e homogêneo, mas desde muito cedo é possível identificar situações de conflito denotando as diferenças de opinião dos sujeitos que viveram no período e deram forma ao próprio conceito de domesticidade.

Sendo assim, a reflexão deve considerar que manuais ofertam um padrão a ser seguido que não necessariamente foi adotado à risca, uma vez que há singularidade no indivíduo receptor das orientações. Além disso, há a especificidade do contexto, uma vez que as publicações se deslocam do mundo norte-americano ou europeu para o brasileiro, por exemplo, com suas dimensões continentais. Portanto, é comum nestes manuais que a figura feminina seja idealizada como moça, mãe e mulher de família e que as boas maneiras sirvam como mediação social e prática definidora de padrões comportamentais nas relações sociais, porém,

É certo que nem sempre as mulheres se espelharam nas imagens construídas sobre elas. E é evidente que os modelos não descrevem a realidade, esta muito mais rica e cheia de possibilidades. Entretanto, é importante conhecer as representações que prevalecem em cada época, pois elas têm a capacidade de influenciar os modos de ser, agir e sentir das pessoas, os espaços que elas ocupam na sociedade e as escolhas de vida que fazem (PINSKY, 2012, p. 470).

Enfim, a perpetração dos papéis de gênero pelos manuais se dá pela disciplinari- 
zação dos corpos, com gestos controlados que permitem a interpretação e o reconhecimento do indivíduo conforme regras sociais predeterminadas. De acordo com Clements (1993), há um universo socialmente sancionado que constrange e direciona à adoção de uma postura em detrimento de outras, justamente o tipo de sanção que cria o gênero como algo distinto da determinação biológica - algo demonstrado com clareza, no que tange este trabalho, pela etiqueta.

Entre as várias definições de etiqueta disponíveis, a ideia de conjunto cerimonial, formas cerimoniosas, regra, normas e estilo associam-na a esse princípio civilizador dos modos e modas. Acosta e Bastos (2012, p. 4) relacionam-na "ao respeito ao próximo, amabilidade, gestos corteses que enfatizam a importância do outro", resultando em relacionamentos harmônicos e agradáveis. Há toda uma produção bibliográfica dedicada exclusivamente à propagação das atitudes esperadas por cada segmento da sociedade. Dois exemplos pertinentes aqui são o Thesouro de Meninas e o Código do Bom Tom, publicação setecentista e oitocentista, respectivamente, ambas de procedência estrangeira que foram reeditadas inúmeras vezes no Brasil - disponíveis até hoje no mercado editorial. Gonçalves Filho (2011, p. 204) enaltece tais publicações por "fornecer indicadores do modo como eram selecionados e apresentados determinados saberes considerados pertinentes de serem repassados às crianças", pois foram pensadas como obras de referência por um longo tempo.

O ritual do chá ${ }^{2}$, por exemplo, demonstra como a comensalidade está imbuída pelas propostas padronizadoras dos manuais de etiqueta. Tocchetto (2010) afirma que a incorporação do chá nos ambientes domésticos foi regrada por uma literatura especializada que indicava, também, o ambiente material que deveria ser organizado para o sucesso de uma de suas principais funções - a exibição de status socioeconômico dos anfitriões. É interessante avaliar o quanto o chá e os papéis de gênero dialogam na historiografia - Annie Gray e Mary Heath trazem importantes contribuições ao debate. Gray (2008) ressalta como o chá foi associado às mulheres ao longo da história, mesmo quando perdeu sua identidade aristocrática e tornou-se uma ocasião significativa de sociabilidade das classes médias. Ainda que a autora perceba uma conotação negativa de indolência e imoralidade, devido ao 'incentivo ao papo furado' nos chás da tarde presididos por mulheres no período vitoriano inglês, Gray valoriza o evento social como um caminho para rupturas de tradições conservadoras e machistas. Por outro lado, Heath (2012) tem uma interpretação muito mais implacável sobre o ritual do chá e sua associação com o feminino, concluindo que este não foi um domínio escolhido por mulheres, resultando diretamente de uma cultura patriarcal de subserviência e aprisionamento que era transmitida, inclusive, de mães para filhas. Logo, ao contrário de Gray, Heath vê nos manuais e na etiqueta do chá um fator estagnante ao progresso das mulheres. Equilibrando abordagens semelhantes às duas autoras, Beddoes (2014) vê no chá
2 Beddoes (2014) explora como o chá e seu ritual se tornou ícone da britanidade, consolidando identidades femininas e domésticas em oposição ao ambiente masculino e público das cafeterias. 
um símbolo dos ideais de comportamento e educação refinados, em um momento que sociabilidades poderiam ser vistas tanto como benéficas ao desenvolvimento social de mulheres de classe alta quanto nocivas à ética do trabalho e à responsabilidade da classe trabalhadora. Democratizado, na aurora do século XX, o chá tornar-se-ia um ícone de sobriedade e respeitabilidade, normatizado por inúmeros especialistas.

A palavra impressa não é, portanto, o único instrumento para inibir e moldar comportamentos, pois o mesmo ocorre com o cenário formado pela materialidade que nos cerca, informando o que é apropriado ou inapropriado (MILLER, 2010, p. 50). De fato, a etiqueta, enquanto pedagogia da qual os autores falam, repercute em uma ritualização que demanda a adequação dos objetos e espaços cotidianos e seus usos, criando o cultivo de rotinas ideais visíveis e, quando necessário, repreensíveis.

Dessa forma, bem como os manuais, a cultura material igualmente foi alvo de estudos que a colocaram como agente dos códigos de postura, como Bezerra (2014b) que vê nos utensílios oitocentistas de mesa e cozinha uma proposta de estética dos espaços e dos comportamentos guiada pelo processo civilizador capitalista. A autora argumenta que objetos em louça, por exemplo, permitiram à elite brasileira

\footnotetext{
Materializar seu pertencimento ao modelo hegemônico de bem-estar e estar bem no mundo organizado pela Inglaterra e pela França. A ritualização das refeições, atuando como marcadores e indicadores sociais, principalmente o jantar e o chá, cumprem essa função ritualística integradora de pertencimento (BEZERRA, 2014b, p. 1093).
}

Outras como Tocchetto (2000) e Carvalho (2015) também destacam o quanto a casa é o suporte material das práticas cotidianas e como a exibição doméstica regrada do corpo feminino vem acompanhada de inúmeros acessórios materiais. Entre as matérias-primas principais que se verificam nessas situações está a louça, um tipo cerâmico industrializado abundante entre os brinquedos selecionados nesta análise. Soares (2011), ao refletir sobre a vida material oitocentista, atesta que louças representavam bom gosto, bons modos e poder aquisitivo, configurando significados que iam além da estética. Além disso, retomando Gray (2008, p. 50), a cerâmica foi muito utilizada como metáfora para a virtude feminina, pois "louças quebravam com facilidade - um motivo para ser estimada era porque seu manuseio correto poderia ser usado para demonstrar familiaridade e, por conseguinte, riqueza e classe"3. Assim, a aptidão e o conhecimento dos ritos do chá, por exemplo, denotavam o controle do ambiente imediato e a virtude intacta das mulheres desenvoltas nas artes da domesticidade.

Neste âmbito de pesquisas que se dedicaram à transmissão de certos comportamentos, em especial relativos ao universo feminino, é interessante pensar no recorte da infância, uma vez que seria neste intervalo da vida que os esforços educativos teriam um caráter mais influente e, mesmo, impositivo - permitindo introjetar ideias de conduta e

\footnotetext{
${ }^{3}$ No original, "china broke easily - one reason it was prized was that the correct handling of it could be used to show familiarity and therefore wealth and class".
} 
etiqueta. Porto (2008, p. 89) atenta para o fato de que crianças deixam poucos registros diretos, sempre intermediados pelo olhar adulto - "pessoas rememoram suas infâncias, e há objetos, brinquedos etc., mas tudo é trazido ao campo de estudo pelos adultos". Por conseguinte, conclui, faz mais sentido abordar historicamente a infância do que as crianças.

Considerada um fenômeno social e cultural com variabilidade espacial e histórica, a infância gera muito debate por se tratar de um conceito recente, aplicado mais como categoria de análise do que como unidade etária fixa. A introdução da criança no mundo que a cerca se dá das mais variadas formas, além da educação formal escolar, seja por meio de publicações como os manuais citados ou pelo contato com elementos da cultura material tidos como adequados à formação de indivíduos saudáveis, dóceis e 'normais'4. Trata-se, mais uma vez, da questão da disciplinarização dos corpos, "a fim de transformá-los em adultos socialmente aceitos" (NASCIMENTO; BRANCHER, 2008), fazendo do lúdico, nas palavras de Lemos (2007), um dispositivo de governo das crianças.

Sena (2010) observa que a primeira regra aprendida pelas crianças é o silêncio. No caso das meninas, a fala é ainda mais cerceada, associada à vergonha, à discrição e à moderação - todos elementos característicos do modelo feminino discutido anteriormente. No entanto, é importante não perder de vista que são adultos que constroem expectativas em torno das personalidades infantis generizadas, apesar de estudos como o de Cunha (2013), voltado à investigação de falas das crianças, que evidencia como ocorre a naturalização de papéis e comportamentos entre meninos e meninas ${ }^{5}$.

Mais uma vez, o exemplo do chá tem seu mérito. Mills (2010) relembra como aparelhos de chá em miniatura foram estudados como exemplo de pais vitorianos ensinando às meninas a domesticidade culta. Porém, a realidade é muito mais complexa por tais objetos também estarem associados à posse adulta. Ainda assim, não há dúvida de que bonecas e jogos de cozinha tiveram, em determinado momento, entre outras possibilidades, a intenção de incutir hábitos e reproduzir determinados papéis sociais femininos.

Nem sempre é simples definir um objeto como brinquedo. De acordo com Sousa e Melo (2009, p. 2), "muitos brinquedos não nasceram como artigos lúdicos, integrando, portanto, outras redes como as ritualísticas, comemorativas, comerciais, decorativas". As autoras argumentam que é a partir do momento em que a criança se apropria do objeto que ele se torna, enfim, brinquedo. Convém ressaltar, no entanto, que o brinquedo não representa a totalidade da cultura material da infância, principalmente porque as crianças não costumam ser responsáveis diretas pela produção e controle dos objetos com os quais interagem, predominando uma materialidade própria do mundo adulto (BROOKSHAW, 2010).

Por fim, partindo da instrumentalização dos gestos por meio da etiqueta, um pa-
4 Segundo Romero (2010), crianças em geral manipulam (e, às vezes, produzem) três tipos de artefatos: brinquedos, réplicas de objetos em menor escala e peças do universo material adulto, como objetos associados à maternidade, por exemplo.

${ }^{5}$ Cunha (2013, p. 36) percebe que "aos meninos cabe o movimento, a liberdade, a correria. Às meninas cabe a passividade, as atividades e os utensílios que compõem uma casa". 
drão que visa uniformizar o feminino em diferentes faixas etárias, o raciocínio pôde ser ampliado a fim de contemplar a cultura material que acompanha a concretização das atitudes idealizadas. A infância, como um estágio privilegiado na disciplinarização dos corpos, tem nos brinquedos uma variedade material com alto potencial para cultivar os padrões de comportamento considerados adequados. Todavia, a memória opera montagens, conscientes ou inconscientes, da história e, no caso do conjunto de brinquedos da primeira metade do século XX que sobreviveu para chegar ao museu, tornou-se documento do seu contexto de produção, "mas também das épocas sucessivas durante as quais continuou a viver, talvez esquecido, durante as quais continuou a ser manipulado, ainda que pelo silêncio" (LE GOFF, 2003, p. 538).

\section{SENTIMENTOS: O BRINQUEDO RESSIGNIFICADO COMO MEMÓRIA}

O passado, este recorte temporal incerto definido pelo presente, tem uma série de efeitos sobre nós. É pedagógico, quando usado como exemplo. É nostálgico, quando contraposto com a dura realidade do presente. É obscuro, quando seus vestígios são escassos. É plural, quando nos dedicamos a pensar em suas infinitas possibilidades. Sobretudo, é outro. É diferente. Quem argumenta a favor desse raciocínio é Lowenthal em sua obra The past is a foreign country (1985), afirmando que o reconhecimento da diferença do passado é o que nos leva a preservá-lo e, em contrapartida, a preservação é o que torna esta diferença ainda mais aparente. A existência do passado está, enfim, no presente, pois é nesse tempo atual e efêmero que decisões são tomadas acerca do que é o passado, de quais elementos o definem e sobre como devemos proceder em relação a eles. Portanto, ocupar-se com as coisas de ontem é um jogo intrincado de poder sobre $\mathrm{o}(\mathrm{s})$ outro(s).

Sendo assim, o alcance dos discursos acerca do passado está pautado pela relação entre conteúdo e abordagem, consubstanciado pela materialidade disponível daquilo que consideramos o patrimônio tangível e pela intangibilidade, por exemplo, da memória - esta, um instrumento de poder (LE GOFF, 2003). Há vestígios do passado, há memórias que compõem e cercam estes vestígios, há o intento da preservação e há os sujeitos responsáveis pela seleção.

Os brinquedos que chegaram ao museu foram guardados, e com muito cuidado preservados no seio familiar, conservados apesar da passagem das gerações e das muitas mãos que os manipularam. Mas houve aqueles que não sobreviveram, por serem frágeis, efêmeros, por terem sido esquecidos, perdidos, quebrados. Schrijnemaekers (2012, p. 11) afirma que "tirar, guardar, remover e banir objetos mostra muito bem essa negociação que é o arranjo da casa: é algo que vai muito além do senso estético ou das condições financeiras". Segundo a autora, trata-se de um processo afetivo e emocional, além 
de busca e consolidação do status almejado. Da mesma maneira, Miller (2010) identifica os objetos de uma dada casa como lembranças cuja decisão de descartar alguns e manter outros é parte crucial da gestão ativa da memória externalizada dos indivíduos.

A bibliografia voltada à cultura material identifica os chamados objetos biográficos como mais suscetíveis à permanência, em oposição ao objeto protocolar, facilmente substituível (MORIN, 1969). Agindo como prova e parte da narrativa que conforma o indivíduo, são mantidos em condições especiais, muitas vezes fora do espaço cotidiano que ameaça seu desgaste ou, em última instância, sua destruição. Reiterando que brinquedos são também parte da vida material adulta, é preciso perceber como no processo seletivo de guardar/descartar, a vivência do mundo infantil perdido pelo passar dos anos e pela chegada à vida adulta ganha cada vez mais um sentido positivo, muitas vezes em detrimento da percepção de dificuldades e problemas atravessados na infância. Schlereth (1985) salienta o quão fragmentárias e temerosas podem ser nossas memórias dos tempos de criança, em paralelo à condição fantasiosa e divertida. A justificativa, segundo ele, está na característica deliberadamente pequena dos vestígios da infância, tornando-a manejável, algo que um adulto segura em suas mãos com facilidade.

Esse manejo inclui também a 'invenção' de coleções. Almeida (2012, p. 184) ressalta que "os objetos que formam uma coleção não existem em estado latente; precisam ser escolhidos, classificados e 'possuídos"'. Isto se aplica tanto ao âmbito privado quanto ao público, pois a mesma lógica vale tanto para quem guardou os brinquedos em casa quanto para o museu que os acolheu em seu acervo. Colecionar, essa prática característica do Ocidente moderno, tem muitas nuances entre os sujeitos que a adotam e, no que tange a brinquedos, é frequente que seus colecionadores sejam mulheres, algo que o referido culto da domesticidade já atrelava às inclinações femininas ${ }^{6}$. Em um estudo sobre coleções do MP que compõem o mesmo conjunto do acervo de brinquedos aqui em questão, os autores Müller e Corrêa (2017, p. 256) observaram na entrevista com a doadora que foram "as mulheres do lado materno $\mathrm{d}[\mathrm{a}]$ interlocutora, que desempenharam o papel de guardiãs de uma dada memória familiar, produzindo, selecionando, organizando e investindo afetos" nos mais variados artefatos.

A escolha feita pela doação ao Museu Paranaense de suas memórias materiais familiares, como perceberam Müller e Corrêa nas entrevistas que conduziram, não foi de maneira nenhuma aleatória, pois já havia uma relação preestabelecida com a instituição em ocasiões passadas nas quais empréstimos de diferentes objetos foram solicitados para compor exposições temporárias. Isto é, o contato com a equipe e o conhecimento mais próximo do fazer institucional facilitou na tomada da decisão que conduziu os tesouros das meninas, entre vários outros artefatos, ao território museal.

Guedes (2004, p. 39) observa que "a maioria das pessoas tem a tendência de doar
6 Embora sejam necessários dados mais concretos acerca disso, a afirmação se encontra em Schlereth (1985), onde mais discussões são conduzidas a respeito. 
os brinquedos usados para obras de caridade ou até jogarem fora”, situação que a autora atribui ao desconhecimento que a população tem com relação ao interesse dos museus em suas vivências infantis. Isto também reflete a percepção difundida entre a população de que museus históricos acumulam objetos de estética mais artística ou muito antigos, associados a determinados personagens.

Porém, as renovações do pensamento social e científico na segunda metade do século XX incluíram a ampliação do que significa "objeto de museu", provocando uma alteração profunda em políticas de aquisição antes conservadoras e elitistas. Portanto, se há uma tendência em áreas como a Pedagogia em valorizar brinquedos populares, que se valem da reutilização do lixo ou são confeccionados à mão com materiais simples (SOUSA; MELO, 2009), esta também se apresenta nas instituições de memória que pretendem direcionar suas práticas preservacionistas para as manifestações mais fugazes e intangíveis como, por exemplo, as brincadeiras de rua e os jogos de improviso.

No museu, o brinquedo ganha caráter público e coletivo, deixa de ser significativo para um indivíduo para atuar como representante de toda uma classe, de uma etnia ou de uma localidade. Em suma, o objeto assim ressignificado, tornado fonte historiográfica e sacralizado pelo museu apresenta uma biografia muito rica ao pesquisador. Não apenas seus significados são múltiplos como podem diferir de objetos semelhantes, devido ao cuidado que lhe foi dedicado. Reconhecida essa incerteza e valorizados os caminhos que trouxeram este acervo até o Museu Paranaense, o maior desafio, talvez, se apresenta: como musealizar significados intangíveis?

\section{(OUTROS) USOS: O LUGAR DO BRINQUEDO NO MUSEU}

Desde finais da década de 1980, com a publicação do Thesaurus para acervos museológicos de Ferrez e Bianchini (1987), brinquedos são documentos museológicos incontestes, categorizados junto ao Lazer/Desporto, embora não escape às autoras a complexidade própria destes que se confundem com os artefatos em escala reduzida que poderiam ter outra função, alheia ao divertimento ou à educação infantil. No entanto, tais objetos compõem acervos de museus desde muito antes, como indica Guedes (2003) no que se refere aos brinquedos do Museu Histórico Nacional, coletados nos primeiros anos de funcionamento daquela instituição.

O objeto identificado como brinquedo apresenta uma dualidade interessante ao museu, uma vez que sua conotação aparentemente infantil evoca também no público adulto uma série de sentimentos: afeto, nostalgia, estranhamento, curiosidade, empatia; estas múltiplas sensações do visitante (seja ele adulto ou criança) facilita seu envolvimento com a história que o circuito pretende contar, potencializando o impacto re- 
flexivo de uma exposição bem planejada. Neste contexto, mesmo a ausência de alguns tipos de objetos, a falha em representar certos sujeitos ou a invisibilidade de memórias esquecidas podem ser exploradas como pontos de contraste às vitrines preenchidas por conjuntos materiais específicos de determinados grupos sociais ou culturais. A interpretação depende, enfim, da proposta efetivada pela experiência da visitação.

Se muitas lacunas são encontradas nas coleções museológicas, há igualmente muito a ser explorado em cada uma delas - conforme Pereira (2009), todo brinquedo carrega em si a época na qual foi produzido, o mundo que o gerou, a educação que propunha, um projeto de sociedade. Aliás, não são poucos os autores que argumentam o quanto a história da moda e da tecnologia está documentada em bonecas e carrinhos, principalmente do século XIX em diante. Isto é especialmente válido para os brinquedos industrializados, acompanhados de uma infinidade de dados complementares - transformados em fontes pelos historiadores - tais como anúncios em jornais, estatísticas dos fabricantes, campanhas publicitárias e a utilização de todo o potencial midiático com histórias em quadrinhos, animações e filmes.

O papel destes brinquedos no museu parece se delinear como uma oportunidade de valorizar a criança enquanto sujeito nas narrativas do passado. Brookshaw (2010) pondera que a ausência de crianças em exposições perpetua a ideia de que o passado foi povoado somente por adultos, ou que a passividade e a insignificância marcam o lugar percebido da criança na sociedade como um sujeito que não faz história, apenas a aprende.

Por outro lado, crianças e seus objetos têm um apelo forte entre o público adulto, que romantiza e reverencia a infância como um período positivo, povoado por memórias calorosas. Roberts (2006) chega a equiparar museus da infância a exposições somente de brinquedos, nos quais a criança é isolada da realidade adulta em uma terra de conforto e alegrias, reforçando uma imagem idealizada. Como alternativa, a autora sugere que os aspectos mais positivos, como brinquedos e jogos, sejam balanceados com os menos atrativos, ou seja, a pobreza, a subnutrição e o trabalho infantil - algo que efetivaria um museu mais controverso e provocativo. A limitação das culturas materiais presentes em museus neste sentido é flagrante, portanto Roberts propõe a utilização de outros métodos expositivos, como reproduções fotográficas e depoimentos em áudio e vídeo.

No caso da exposição temporária Tempo de Brincar ${ }^{7}$, elaborada em 2015 como uma primeira tentativa de problematizar o conjunto de brinquedos incorporado ao acervo do MP, houve um esforço em refletir também sobre coleções preexistentes na instituição: quais crianças eram estas, no Paraná do século XX? Filhos de imigrantes, de ascendência europeia, com boas condições financeiras e acesso à produção mais recente
7 Dados técnicos, imagens e equipe da exposição, fruto também das discussões do Grupo de Trabalho Cultura Material e Infância, podem ser consultados na plataforma Pergamum Museus, sob o código 160771. Cabe lembrar que já houve, em 2003, outra exposição de enfoque similar, intitulada "O brinquedo, a criança e o tempo", da qual se encontra um folder no arquivo permanente da instituição. Embora sejam poucas as informações a respeito da proposta e dos resultados pretendidos/alcan-

çados, sabe-se que em paralelo ocorreu uma oficina de restauro e conservação de bonecas antigas e uma palestra sobre literatura infantil em parceria com o Colégio Positivo. 
das indústrias de brinquedo internacionais eram a norma? Partindo do pressuposto que a resposta é negativa, algumas soluções foram encontradas como forma de incluir na referida exposição pequenos pontos de provocação. A predominância de brinquedos de fabricação industrial pode supor uma sucessão linear que substituiu e eliminou a produção artesanal, entretanto,

$\mathrm{O}$ avanço da industrialização não causou apenas opções novas em brinquedos mais modernos, mas também uma diferenciação na criação dos brinquedos populares que adquiriram uma característica até então inovadora em sua construção: peças manufaturadas utilizando já produtos industrializados. A união do tradicional e o moderno no mesmo objeto. (...) Um exemplo desta inovação é a peteca, que mesmo a que é feita à mão, utiliza-se a borracha e penas sintéticas (CARVALHO et al, 2014, p. 10)

A solução de hibridismo nas matérias-primas mencionada compõe não apenas os brinquedos populares, como também muitos brinquedos indígenas confeccionados em beiras de estrada como formas de sobrevivência, à venda para turistas que não necessariamente vão utilizá-los como brinquedos, considerando-os artesanato.

Brinquedos indígenas, a propósito, são abundantes no acervo etnográfico do $\mathrm{Mu}$ seu Paranaense, permitindo que bonecas Karajá e miniaturas de animais em cera de abelha ou madeira fossem inseridas entre as bonecas de porcelana e os soldadinhos de chumbo e seus camelos nesta mesma exposição. Foi uma oportunidade de pensar nos grupos indígenas que tem sua própria concepção de infância, com seus próprios significados e culturas materiais. A decisão por expor a variedade do acervo, em termos de matéria-prima, formas de brincar, cores, tamanhos e épocas, esteve enfim pautada na recomendação de Breier (2005) de dar historicidade aos objetos, substituindo a mera contemplação pelo incentivo ao pensamento crítico.

O fato é que o museu, com seu status de lugar de memória, representa um ambiente privilegiado para a análise do jogo entre vestígios do passado, memórias sobre/ ao redor desses vestígios e sujeitos que os preservam e selecionam (para guardar, para expor, para falar a respeito). Além disso, permanece o questionamento: deveria o museu manter-se na contemporaneidade tão somente como um espaço que acumula e conserva vestígios, sendo que, de acordo com Bruno (2009, p. 21), "seus principais problemas e, em muitos casos, retrocessos, correspondem exatamente ao acúmulo - muitas vezes desmedido -, de artefatos, coleções e acervos"? Diversos autores compartilham estudos de caso nos quais ficam evidenciados os problemas da sacralização do passado e de seus vestígios, além do risco da naturalização de ideias acerca do patrimônio.

Todavia, para que os profissionais de museus possam agir conscientemente, para que tornem seu papel no jogo de poder das memórias e identidades mais transparente e, finalmente, para atender às exigências de uma contemporaneidade comprometida com a reflexão crítica daquilo que a compõe, é preciso primeiro se apropriar das muitas vidas 
contidas nos acervos e articulá-las aos novos significados construídos pela instituição. É dessa forma que a documentação museológica se torna fundamental para qualquer reflexão, pois é imprescindível na compreensão da intangibilidade da cultura material assumida como sentimento, uma vez que narrativas de afeto pontuam a inserção de objetos cotidianos no domínio privilegiado do patrimônio.

Como um objeto age sempre a partir de um lugar, pode vir a se tornar metonímia cultural, "porque está ligado à experiência dos sujeitos com e no mundo, posto que ele representa uma porção significativa da paisagem vivida" (SILVEIRA; LIMA FILHO, 2005, p. 40). É nesse sentido que a materialidade pode ser compreendida em sua intangibilidade, pois a concretude física dos artefatos sempre é complementada, seja no uso cotidiano ou na análise do pesquisador, por suas relações abstratas e, principalmente, dinâmicas com os sujeitos. Independente de uma peça se encontrar sob a redoma de vidro de um museu ao invés de guardada em uma prateleira na residência de seu comprador original, sua historicidade remonta a todas as etapas de sua trajetória, como um viajante no tempo e no espaço.

A construção coletiva da poesia da recordação (ASSMANN, 2011), no caso dos museus, tem início na doação pelo sujeito proprietário ou herdeiro de determinado item da cultura material, da sua cultura material. Este personagem já chega ao museu com um posicionamento predefinido acerca da importância daquilo que está doando, com uma narrativa a ser passada adiante. Por sua vez, a documentação desta informação complementar ao objeto, operada pela instituição que o acolhe, finaliza a linearidade daquela trajetória. O que às vezes não está claro no registro escrito desta trajetória, mesmo que o doador esteja consciente disso, é a etapa que define o desejo de perpetuação. Ora, entre perder a utilidade consumível e tornar-se objeto de museu, deve haver uma vontade de continuidade, deve haver um esclarecimento da possibilidade de eternização nas mãos de sujeitos ou instituições legítimos para a função. Ir ao museu no intento de doar um vestígio material da sua vida é um movimento impulsionado por sentimentos, quaisquer que sejam. Pode surgir do medo do esquecimento, do apetite pela nostalgia compartilhada ou do exercício do desapego emocional do passado, mas o intuito da permanência de memórias, de personagens e de histórias pessoais está sempre presente.

Finalmente, a poesia se completa na exposição, quando o visitante adentra o circuito de sentidos atribuídos a conjuntos materiais, dispostos de maneira a desencadear determinadas interpretações do passado, embora sempre sujeitas ao meio cultural de proveniência do público. Entretanto, considerando as trajetórias singulares que alguns doadores associam aos objetos que submetem à guarda do museu, como seriam as mensagens recebidas pelo público visitante caso a narrativa expositiva contemplasse essas delimitações à biografia cultural das peças? Com certeza, atrelar a um artefato uma história particular de uso e contexto dificulta que ele seja compreendido em uma perspec- 
tiva mais ampla de representação do passado. Mas muitas vezes omitir a particularidade em nome do abrangente também obscurece a possibilidade de experimentar empatias novas. Retomo mais uma vez a ideia da cultura material como metáfora: são muitos os significados, é indiscutível. Para explorá-los é necessário compreender o que faz de cada acervo um conjunto único de vestígios do passado, análise que parte de elementos relativos aos doadores e sua proveniência, mas que também se refere à materialidade em si.

Do ponto de vista da matéria-prima, o conjunto selecionado para este trabalho abrange categorias muito diversas (Tabela 01), sendo que há casos em que os materiais surgem misturados em uma única peça - como os talheres em porcelana e cabo de madeira (MP.5689 a MP.5693) ou o delicado galheteiro com estrutura de metal e frascos de vidro encaixados (MP.5671). Ainda assim, chama à atenção a quantidade expressiva de materiais cerâmicos (seja porcelana ou faiança fina) presentes entre os objetos recebidos sob a alcunha de 'brinquedos' - 62,9\% da amostra apresenta pequenas xícaras, bules e pratos fundos ou rasos, numa reprodução miniaturizada bastante fiel de finíssimos serviços de chá ou de jantar utilizados nas mesas mais bem equipadas, das famílias mais abastadas.

\begin{tabular}{l|cc}
\hline \multicolumn{1}{c|}{ Material } & Quantidade & Total \\
\hline Cerâmica (porcelana, faiança fina) & 148 & \\
Vidro & 42 & \\
Metal (ferro, alumínio, ágata) & 23 & 235 \\
Plástico & 10 & \\
Papelão & 6 & \\
Madeira & 5 & \\
Vime & 1 & \\
\hline
\end{tabular}

Tabela 1 - Tipologias materiais na amostra de brinquedos selecionada.

Análises mais técnicas da 'louça' enquanto cultura material e da variabilidade nas composições decorativas podem ser encontradas em Morales (2014), com exemplos extraídos do acervo do setor de Arqueologia do Museu Paranaense - neste momento, priorizo questões como a procedência dos aparelhos de chá e jantar em miniatura. Ambas as doadoras do acervo selecionado neste trabalho são de famílias de ascendência germânica, algo que pôde ser verificado quando os álbuns e fotografias familiares foram inseridos na catalogação e as narrativas repassadas à equipe davam conta de férias e temporadas passadas na Suíça, na Áustria e na Alemanha, para reencontrar parentes e conhecer a terra da qual emigrara a família. Tal procedência também está clara na 
primeira atribuição associada aos conjuntos de artefatos doados, prestando atenção aos termos de doação.

Nos três termos registrados em 2015 pelo setor de Museologia encontram-se listados com descrições primárias os quase 800 itens doados na ocasião. Nestes documentos está descrito oito vezes que em dado objeto consta alguma inscrição 'em alemão', pelo menos uma vez fala-se a respeito da 'origem alemã' da peça, 72 peças são diretamente referenciadas como provenientes da Alemanha e outras nove acusam a inscrição 'Germany'. Ou seja, mesmo antes de passarem pelo processo de catalogação e inserção na documentação museológica que normalmente exige análises que aferem forma, função e procedência, já havia um direcionamento por parte das narrativas coletadas no momento da doação que atribuía uma forte presença de materialidade originária do país europeu. Confrontando as listas anexas aos termos de doação, é perceptível que muitos dos artefatos listados como 'alemães' não terão sua origem confirmada de maneira absoluta, pois compõem um conjunto material desprovido de etiquetas, selos de fabricação ou documentos comprobatórios que dariam conta de legitimar a dita proveniência por exemplo, roupas, lenços e brinquedos sem marca. Numa casa de leilões, na qual se lida com somas consideráveis negociadas por colecionadores cuja base de interesse está diretamente atrelada à autenticidade daquilo que adquirem, tal fragilidade da informação pode ser um problema. Entretanto, no que diz respeito a um museu histórico, dadas todas as discussões que valorizam o jogo da seleção de materiais, da construção de conceitos e da contextualização e ressignificação de memórias, a caracterização que acompanha a oferta dos artefatos pelas doadoras ao museu tem sua importância independente da autenticidade. O discurso que remete à Alemanha as ligações afetivas dos objetos faz sentido no seio familiar tradicional do qual as doadoras fazem parte e se encaixa na formação histórica de cidades como Curitiba, cuja imigração compôs um cenário importante na primeira metade do século XX.

Entre os brinquedos selecionados, há um aparelho de chá e um conjunto de toucador que apresentam selos de fabricação alemã. O serviço de chá em porcelana decorada com pintura marrom, composto por 14 peças $^{8}$, foi produzido pela fábrica Bauscher Bros. entre 1920 e 1945, na região de Weiden na Bavária. Já o conjunto composto por caixa, urinol, bacia, gomil e saboneteira de porcelana ${ }^{9}$, decorados com impressão por transferência em tom rosa, provém da fábrica Villeroy \& Boch, de Wallerfangen, produzido entre 1900 e 1930. Embora em escalas diferentes, tanto a miniatura do utensílio de mesa quanto o jogo de quarto traduzem bem as propostas abordadas anteriormente. São exemplares finamente fabricados, com o mesmo esmero que se encontraria nas versões de tamanho regular, reproduzindo um cenário muito vívido para a brincadeira infantil.

Contudo, é interessante perceber que, em um dos conjuntos doados, jogos de chá 
e jantar de produção local estão mais presentes. Há pelos menos três fábricas do Paraná cujos selos estão aparentes nas pequenas louças - dois aparelhos de chá e um serviço de jantar. A Cerâmica Campo Largo (CCL), sediada em cidade do mesmo nome na região metropolitana de Curitiba, e a Cerâmica Iguassú, com unidade em Curitiba, são um caso peculiar na amostra, pois suas decorações fizeram com que as peças se misturassem a tal ponto que, se ignorado o selo na parte inferior, parecem compor o mesmo jogo.

A explicação está na técnica decorativa escolhida, pois o uso do decalque, ou decalcomania, implica na repetição em série de figuras - diferenciadas apenas pela pintura. A aplicação de desenhos impressos em filme ou papel sobre a superfície da peça se popularizou no final do século XIX, mas de acordo com Souza (2010) a produção nacional aderiu à técnica principalmente após a II Guerra Mundial. Sendo possível datar a produção e comercialização destes jogos da CCL e da Iguassú na década de 1940, vê-se que já ocorre um processo de padronização no mercado industrial neste período. Preservadas lado a lado, entregues ao museu em conjunto e mantidas na reserva técnica como um mesmo grupamento, dada a sua decoração similar, a única leve diferenciação que se faz a olho $\mathrm{nu}$ (repito, ignorando o selo na base) é a craquelagem das peças. Indício da qualidade da pasta, da cobertura de esmalte e do processo de queima que adere um ao outro, fica evidente que a CCL atingiu um produto mais bem acabado que envelheceu com poucos defeitos, enquanto o craquelamento das peças da Iguassú é muito mais aparente.

Da mesma época é a miniatura de aparelho de chá da Fábrica de Louças Evaristo Baggio, sediada em Curitiba em meados do século XX, no qual se percebe o mesmo problema na qualidade das peças. Não obstante, as peças de fabricação local são um testemunho do alinhamento do projeto de vida material do final do século XIX e da primeira metade do século XX, com objetos de inspiração europeia que são fabricados no Brasil para públicos interessados em replicar modismos e tendências, comportamentos e práticas verificáveis nos gestos e nos costumes. A proposta inclui, portanto, adultos em suas aspirações e crianças em sua educação posta em prática pelos mais velhos que a cercam, pautados por leituras, ideais e discursos de modernidade, civilidade e etiqueta.

As peças entre MP.5618 e MP.5623, um jogo de chá incompleto, são decoradas por decalques com crianças brincando com aros conduzidos por arames, tocando instrumentos musicais, interagindo com diferentes brinquedos ou com animais; o mesmo aparece nas xícaras, pratos e bules entre MP.8414 e MP.8444, representando também brincadeiras de aviador e a prática de diferentes esportes na decoração. É interessante perceber como todas as cenas representadas nesses decalques parecem se desenrolar fora de casa, envolvendo meninos e meninas juntos - uma curiosa oposição à leitura que se faz dos jogos de louça como apenas um estágio no futuro aprisionamento doméstico feminino. As crianças decalcadas surgem lado a lado, divertindo-se das mais variadas formas, em gramados, próximas a lagos. O cenário lúdico retratado nessas peças reme- 
te a uma infância vivida e compartilhada por meninos e meninas, muito embora haja inúmeras pesquisas destacando a atribuição dos espaços público/privado para sujeitos generizados de maneira específica desde tenra idade. A mesma literatura designa as categorias materiais nas quais aparecem tais decalques - isto é, jogos de louça em miniatura - ao universo artefatual feminino, mesmo que se tenham registros artísticos apresentando a brincadeira do chá como um evento do qual tomam parte crianças em geral ${ }^{10}$.

No que diz respeito à escolha de cenas lúdicas para decoração e peças, apesar deste trabalho não versar sobre as demais louças presentes no acervo do MP, cabe lembrar que o setor de História conta com uma xícara fabricada pela Porcelana Mauá (SP) decorada com animais antropomórficos, cujo doador informou ter pertencido à sua irmã que a utilizava em suas refeições quando menina na década de 1940 - uma clara associação da cultura material cotidiana ao mundo fantástico das fábulas infantis. Dessa forma, uma avaliação atenta do conjunto material disponível de fato conversa com as interpretações feitas por muitos pesquisadores, de diferentes áreas, de que em determinado momento entre o final do século XIX e o início do XX os brinquedos miniaturizavam um mundo adulto que os direcionava a certos papéis sociais, de gênero, e a condutas ideais que deveriam ser aprendidas por meio da absorção de padrões comportamentais. Entretanto, os fabricantes de objetos destinados ao público infantil também visaram atender a um imaginário povoado por atividades propriamente desempenhadas pelas crianças em seu divertimento, não engessando a oferta de cultura material à mera noção de 'adultos em formação'.

Em termos da totalidade selecionada, ratifico que a percepção de uma padronização dos comportamentos, em especial das meninas, é algo facilmente verificável. Por outro lado, é perceptível que não se perdeu de vista a dimensão lúdica nas infâncias vividas e guardadas pelas doadoras. Os brinquedos em questão estão, realmente, muito bem preservados - houve carinho em sua manutenção, mais do que simples cuidado. Mas também foram veículos para muitas brincadeiras, seu manuseio é evidente. Não falo apenas de evidências de quebras e pequenos reparos, de peças faltantes ou de desgastes ocasionais. Os brinquedos antigos de louça, de vidro, de madeira, trazidos, em alguns casos, do estrangeiro, se aliaram aos mais novos objetos de plástico e a pequenos itens de lembranças ou de propaganda de marcas diversas para compor um novo cenário na brincadeira de casinha, passando pelas doadoras, suas amigas, filhos, filhas, netos e netas ao longo de quase um século. Assim, chegou ao museu ao mesmo tempo um pequeníssimo porta-salsicha alemão em porcelana, um suvenir de Florianópolis, aquela "terra de sol e mar", e um engradado de refrigerantes divulgando o imperativo do século XX, "Beba Coca-Cola". Resta alguma dúvida de que não há impedimento algum à junção desses três itens, sem prejuízo à lógica nem medo de anacronismos? Este é o ponto ao qual queria chegar: a cultura material é polissêmica. O limite da imaginação expográfica,
${ }^{10}$ Por exemplo, a pintura a óleo "The Children's Party", elaborada por William Hogarth em 1730, no qual se vê um grupo de crianças brincando com suas louças e mobiliários em miniatura, quando seu animal de estimação derruba as peças no chão (GRAY, 2006). 
a análise impedida pela ausência de contexto, a perda da referência... todos são bloqueios que nós impomos a nós mesmos. Talvez a ideia da infância como um tempo mais dinâmico e rico esteja aí para nos lembrar de que dinamismo e riqueza são conceitos que criamos quando adultos, perfeitamente negociáveis.

Os brinquedos selecionados para servirem de objeto de reflexão estão todos disponíveis para consulta online na base de dados do MP. Lá, é possível verificar detalhes que não foram abordados aqui, pois o objetivo foi "penetrar nos cenários invisíveis, sensoriais e valorativos que extrapolam as barreiras impostas por análises pontuais ligadas, por exemplo, à medição dos objetos” (BRUNO, 2009, p. 14-15), enfocando na bibliografia e nas discussões potenciais de seu cruzamento com a materialidade. Ao fim, mais caminhos foram abertos do que fechados, pois os usos tangíveis e intangíveis da cultura material se reinventam, sempre.

\section{CONSIDERAÇÕES FINAIS}

A tríade de conceitos de infância, gênero e cultura material serviu a essa pesquisa como articuladores para uma narrativa a se consolidar na esfera museológica. Um primeiro caminho de análise foi pensar nas pedagogias culturais materiais, relacionando objetos a usos cotidianos adequados a rotinas desejadas, especialmente no que se refere ao controle dos corpos, em geral, femininos. Assim, a louça surge como uma metáfora da virtuosidade na destreza de mulheres que dominam os rituais da comensalidade com seus utensílios e, por sua vez, as miniaturas conferem um treinamento conveniente para futuras esposas e anfitriãs.

Nesse ponto, uma dualidade interessante surge, a do objeto que é ao mesmo tempo um brinquedo e uma ferramenta de transmissão de ideias. Mais tarde, já no museu, um terceiro viés se impõe - a simbologia de uma sociedade, de um tempo, de um grupo específico. No jogo que opõe descarte e permanência, objetos que sobrevivem ao passar dos anos trazem em suas bagagens biográficas tanto preconcepções quanto expectativas, potencialmente explorados pelo novo guardião - o museu - das mais diversas formas.

A coleção de brinquedos aqui analisada, "inventada" pela equipe técnica que os recebeu e os atrelou ao 'brincar de casinha', fornece um ambiente privilegiado de reflexão para esses tópicos. São muitos ainda os caminhos a serem percorridos, as relações a serem estabelecidas e os estudos a aprofundar, pois fica estabelecido, desde já, que a polissemia da cultura material é um benefício a ser mais bem explorado por nós, interessados no passado e em seus significados. 
LEPRINCE DE BEAUMONT, Jeanne Marie (madame). Thesouro de meninas, ou diálogos de uma sábia aia e suas discípulas. Tradução de Joaquim Ignácio de Frias. Lisboa: s/e, 1846.

MUSEU PARANAENSE. Acervo online. Mostra “Tempo de brincar”. Curitiba, 2015. Memória informatizada de exposição temporária aberta ao público entre setembro de 2015 e junho de 2016.

MUSEU PARANAENSE. Arquivo permanente. Mostra "O Brinquedo, a Criança e o Tempo". Curitiba, 2003. 1 p. Folheto elaborado para divulgação de exposição temporária aberta ao público entre outubro e novembro de 2003.

MUSEU PARANAENSE. Termo de doação. Luci Berta Hatschbach ao Museu Paranaense, "Coleção composta por brinquedos, indumentária, fotografias, documentação, numismática e peças diversas”, assinado em 05 de maio de 2015.

MUSEU PARANAENSE. Termo de doação. Maria Luiza de Almeida Scheleder ao Museu Paranaense, "Coleção composta por cento e cinquenta e cinco peças referentes a brinquedos, indumentária, fotografias, cartões postais, documentos e outro”, assinado em 15 de junho de 2015.

MUSEU PARANAENSE. Termo de doação. Maria Luiza de Almeida Scheleder do Museu Paranaense, "Coleção de brinquedos composta por cento e quarenta e nove peças", assinado em 13 de agosto de 2015.

REVISTA Illustrada, n. 150, anno 4, Rio de Janeiro, 15 de fevereiro de 1879.

ROQUETTE, José Ignácio. Código do Bom Tom, ou Regras da Civilidade e de Bem Viver no Século XIX. Paris: Va J. P. Aillaud, Guillard \& Ca, livreiros de Sua Majestade e Imperador do Brazil e El-Rei de Portugal, 1875.

\section{REFERÊNCIAS BIBLIOGRÁFICAS}

ACOSTA, Ana Cristina Maia de Araújo; BASTOS, Sênia Regina. A etiqueta permeando o ambiente hospitaleiro das recepções domésticas. Contribuciones a las Ciencias Sociales, nov/2012, s/p. Disponível em: <www.eumed.net/rev/cccss/22/> Acesso em: 06/10/2021.

ALBUQUERQUE Jr., Durval Muniz de. História: a arte de inventar o passado. Ensaios de teoria da história. Bauru, SP: EDUSC, 2007. 
ALMEIDA, Cícero Antônio de. Objetos que se oferecem ao olhar. Colecionadores e o "desejo de museu". In: MAGALHÃES, Aline Montenegro; BEZERRA, Rafael Zamorano (orgs.) Coleções e colecionadores: a polissemia das práticas. Rio de Janeiro: MHN, 2012. p. 183-200

ARIÈS, Philippe. História social da infância e da família. Rio de Janeiro: LCT, 1978

ASSMANN, Aleida. Espaços de recordação: formas e transformações da memória cultural. Campinas: Editora da Unicamp, 2011.

BEDDOES, Emalee. The art of tea: late Victorian visual culture and the normalization of an international national icon. Dissertação (Mestrado) - University of Birmingham, UK, 2014.

BEZERRA, Ana Paula Gomes. Conjunto de chá e aparelho de jantar: um estudo das elites aracatienses através da cultura material consumida na segunda metade do oitocentos. Anais do XIV Encontro Estadual de História do Ceará, Fortaleza/CE, 2014a, p. 1-15.

BEZERRA, Ana Paula Gomes. 'Bons modos à mesa': a inserção da elite aracatiense no processo civilizador capitalista através dos objetos de mesa e cozinha (1850-1890). Oficina do Historiador, Suplemento Especial: Anais do I Encontro de Pesquisas Históricas, PUC-RS. Porto Alegre: EDIPUCRS, 2014b. p. 1087-1100

BREIER, Ana Claudia Bôer. Museu infantis: uma questão contemporânea. Dissertação (Mestrado em Arquitetura) - Universidade Federal do Rio Grande do Sul, Porto Alegre, 2005.

BROOKSHAW, Sharon. The archaeology of childhood: a museum perspective. Complutum, v. 21, n. 2, p. 215-232, 2010.

BRUNO, Maria Cristina Oliveira. Estudos de cultura material e coleções museológicas: avanços, retrocessos e desafios. In: GRANATO, Marcus; RANGEL, Marcio (orgs.) Cultura material e patrimônio da Ciência e Tecnologia. Rio de Janeiro: MAST, 2009. p. 14-25

CARNEIRO, Cintia Maria Sant'Ana Braga. O Museu Paranaense e Romário Martins: a busca de uma identidade para o Paraná (1902-1928). Dissertação (Mestrado em História) - Universidade Federal do Paraná, Curitiba, 2001.

CARVALHO, Liliane Afonso Pereira de; STORI, Norberto; MOSANER Jr., Eduardo. Brinquedo popular brasileiro das brincadeiras para os museus. Revista Digital Art\&, ano XII, n. 15, nov. 2014, p. 1-14. Disponível em: <http://www.revista.art.br/ 
site-numero-15/11.pdf> Acesso em 20 de mar. 2015

CARVALHO, Vânia Carneiro de. Gênero e cultura material: uma introdução bibliográfica. Anais do Museu Paulista, São Paulo, Nova Série, v. 8/9, p. 293-321, 2003.

CARVALHO, Vânia Carneiro de. Gênero e artefato: o sistema doméstico na perspectiva da cultura material. São Paulo, 1870-1920. São Paulo: Edusp, FAPESP, 2008.

CARVALHO, Vânia Carneiro de. Cultura material, espaço doméstico e musealização. Varia História, Belo Horizonte, v. 27, n. 46, p. 443-469, jul./dez. 2011

CARVALHO, Vânia Carneiro de. Cinderelas, bailarinas e a vida longa das galanterias. Anais da 37a Reunião Nacional da ANPEd, Florianópolis: UFSC, 2015, p. 1-22.

CASTRO, Michele Bredel de. Noção de criança e infância: diálogos, reflexões, interlocuções. Anais do $\mathbf{1 6}^{\circ}$ Congresso de Leitura do Brasil. Campinas: Unicamp, 2007, p. 1-11.

CLEMENTS, Joyce. The cultural creations of the feminine gender: an example from 19th Century military households at Fort Independence, Boston. Historical Archaeology, 1993, 27 (4), p. 39-64

COCHRAN, Mathew; BEAUDRY, Mary C. Material culture studies and historical archaeology. In: HICKS, Dan; BEAUDRY, Mary (eds.) The Cambridge Companion to Historical Archaeology. New York: Cambridge University Press, 2008. p. 191-204

CUNHA, Luciane da Rocha Santos da. Coisa de menina! Coisa de menino! A percepção de gênero através dos brinquedos e brincadeiras na educação infantil. Monografia (Licenciatura em Pedagogia) - Universidade de Brasília, 2013.

FELIPE, Jane. Infância, gênero e sexualidade. Educação \& Realidade, Porto Alegre, v. 25, n. 1, p. 115-131, jan./jun. 2000.

FERREZ, Helena Dodd; BIANCHINI, Maria Helena. Thesaurus para acervos museológicos, $1^{\circ}$ volume, ordem sistemática. Rio de Janeiro: Fundação Nacional Pró-Memória, Coordenadoria Geral de Acervos Museológicos, 1987.

FRISO, Valéria Ramos; SILVA, João Carlos Riccó da; LANDIM, Paula da Cruz. A produção e o design industrial de artefatos para crianças na história - uma revisão. Blucher Design Proceedings: Anais do $11^{\circ}$ Congresso Brasileiro de Pesquisa e Desenvolvimento em Design, v. 1, n. 4, nov. 2014, p. 1-11.

GARRAFFONI, Renata Senna. Arqueologia e história: a busca por um diálogo. In: OLIVEIRA, Terezinha (org.) Antiguidade e medievo: olhares histórico-filosóficos da educação. Maringá: Editora da UEM, 2008. p. 49-60 
GONÇALVES, José Reginaldo. Antropologia dos objetos: coleções, museus e patrimônios. Revista Brasileira de Informação Bibliográfica em Ciências Sociais BiB, São Paulo, n. 60, 2005.

GONÇALVES FILHO, Carlos Antônio Pereira. Livrinhos que eram verdadeiros tesouros: leituras para crianças no Brasil imperial. Revista HISTEDBR On-Line, Campinas, n. 42, p. 200-216, jun. 2011

GRAY, Thomas A. The Old Salem Toy Museum. Winston-Salem, NC: Old Salem Inc., 2006.

GRAY, Annie. 'A moveable feast': negotiating gender at the middle-class tea-table in eighteenth- and nineteenth-century England. In: BAKER, Sera; GRAY, Annie; LAKIN, Kay; MADOWICK, Richard; POOLE, Kristopher; SANDIAS, Michela (eds.) Food and drink in archaeology, vol. 2. Nottingham: University of Nottingham Postgraduate Conference, 2008. p. 46-56

GUEDES, ngela Cardoso. Empatia imediata, elo entre gerações: coleções de brinquedos no museu. In: BITTENCOURT, José Neves; BENCHETRIT, Sarah Fassa; TOSTES, Vera Lúcia Bottrel (org.) História representada: o dilema dos museus. Rio de Janeiro: Museu Histórico Nacional, 2003. p. 135-142

Brinquedos: por uma política de aquisição. Anais do Museu Histórico Nacional, v. 36, 2004, p. 25-40

HEATH, Mary. A woman's world: how afternoon tea defined and hindered Victorian middleclass women. Constructing the past, vol. 13, n. 1, 2012, p. 1-11.

HECHT, Anat. Home sweet home: tangible memories of an uproot childhood. In: MILLER, Daniel (ed.) Home possession: material culture behind closed door. New York: Berg, 2001. p. 123-145

LE GOFF, Jacques. História e memória. Campinas: Editora da Unicamp, 2003.

LEMOS, Flavia Cristina Silveira. A apropriação do brincar como instrumento de disciplina e controle das crianças. Estudos e pesquisas em psicologia, UERJ, v. 7, n. 1, p. 81-91, abr. 2007.

LOWENTHAL, David. The past is a foreign country. New York: Cambridge university Press, 1985.

MAJEWSKI, Teresita; O'BRIEN, Michael. The use and misuse of nineteenth-century english and american ceramics in archaeological analysis. In: Advances in archaeological method and theory, v. 11, Academic Press, 1987. p. 97-209 
MILLER, Daniel. Extracts from Material Culture and Mass Consumption. In: BUCHLI, Victor (ed.) Material culture: critical concepts in social sciences, v. II. London, New York: Routledge, 2004. p. 292-336

Stuff. Cambridge: Polity Press, 2010.

MILLS, Ralph. Miniatures in historical archaeology. Toys, trifles and trinkets re-examined. MA in Historical Archaeology, University of Leicester, Sept. 2010.

MORALES, Martha H. L. Becker. Fragmentos de história: passados possíveis no discurso da arqueologia histórica. Curitiba: Sociedade de Amigos do Museu Paranaense, 2014.

Brincar e guardar: caminhos interpretativos para uma coleção de brinquedos no Museu Paranaense. Anais da XII Jornada de História Cultural, Porto Alegre, 14 e 15 de agosto de 2015. p. 186-198

Fragmentos eloquentes. História Unicap, v. 2, n. 3, jan./jun. de 2015, p. $54-63$

MORIN, Violette. L’objet biographique. Communications, 13, p. 131-139, 1969.

MÜLLER, Caroline; CORREAA, Ronaldo de Oliveira. Coleções familiares na formação do acervo de indumentária do Museu Paranaense, Curitiba-PR. Anais do $4^{\mathbf{0}}$ Congresso Internacional de Memória, Design e Moda, São Paulo, 2017. p. 252-267

NASCIMENTO, Claudia Terra do; BRANCHER, Vantoir Roberto; OLIVEIRA, Valeska Fortes de. A construção social do conceito de infância: algumas interlocuções históricas e sociológicas. Revista Contexto \& Educação, v. 23, n. 79, p. 47-63, 2008.

PEREIRA, Rita Maria Ribes. Uma história cultural dos brinquedos: apontamentos sobre infância, cultura e educação. Revista Teias, v. 10, n. 20, 2009, p. 1-20.

PINSKY, Carla Bassanezi. A era dos modelos rígidos. In: Pinsky, Carla Bassanezi; PEDRO, Joana Maria (orgs.) Nova história das mulheres. São Paulo: Contexto, 2012. p. 469-512

PORTO, Isis Maria Ribeiro. Brincar é coisa séria? Um estudo do brinquedo na cultura da modernidade. Tese (Doutorado em Ciências Sociais) - Universidade Federal do Pará, 2008.

ROBERTS, Sharon. Minor concerns: representations of children and childhood in British museums. Museum and Society, v. 4, n. 3, p. 152-165, 2006 
ROMERO, Margarita Sanchéz. ¡Eso no se toca! Infância y cultura material en arqueología. Complutum, v. 21, n. 2, p. 9-13, 2010.

SAMPAIO, Fernando da Silva. Código do Bom-Tom: comportamento, saúde e regras de etiqueta para mulheres no manual de José Inácio Roquette. Vozes, Pretérito e Devir, v. 1, n. 2, p. 295-308, 2013.

SCHLERETH, Thomas. The material culture of childhood: problems and potential in historical explanation. Material Culture Review, Nova Scotia, Canada, v. 21, spring 1985, p. 365-383.

SCHRIJNEMAEKERS, Stella Christina. "Tira, põe, deixa ficar": notas sobre a negociação do espaço da casa e o seu preenchimento com objetos em famílias de camadas médias. Revista Olhares Sociais, v. 1, n. 1, jan. 2012, p. 1-22.

SCOTT, Joan W. Gênero: uma categoria útil de análise. Educação \& Realidade, Porto Alegre, v. 20, n. 2, p. 71-99, jul./dez. 1995.

SECRETARIA DE ESTADO DA CULTURA, PR. Catálogo do Museu Paranaense. Curitiba: Secretaria de Estado da Cultura, 2006.

SENA, Fabiana. A conversação como modo de distinção no Império: Tesouro de Meninos e Código do Bom-Tom nas escolas brasileiras. Revista HISTEDBR On-Line, Campinas, n. 37, p. 253-265, mar. 2010

SILVEIRA, Flávio Leonel da; LIMA FILHO, Manuel Ferreira. Por uma antropologia do objeto documental: entre a "alma nas coisas" e a coisificação do objeto. Horizontes antropológicos, Porto Alegre, ano 11, n. 23, p. 37-50, jan./jun. 2005.

SOARES, Fernanda Codevilla. Vida material e louças do MHSC. In: BARCELOS, Artur Henrique Franco; PARELLADA, Claudia Inês; CAMPOS, Juliano Bitencourt (orgs.) Arqueologia no sul do Brasil. Criciúma: Ed. UNESC, 2011. p. 161-183

SOUSA, Roselne Santarosa de; MELO, Maria de Fátima de Queiroz e. Resgate de dois objetos lúdicos: seguindo o caminho do pião e do bilboquê. Anais do XV Encontro Nacional da ABRAPSO, Faculdade Integrada Tiradentes, 2009, p. 1-10.

SOUZA, Rafael de Abreu e. Louça branca para a pauliceia: arqueologia histórica da Fábrica de Louças Santa Catarina. Dissertação (Mestrado em Arqueologia) - Universidade de São Paulo, São Paulo, 2010.

SUDJIC, Deyan. A linguagem das coisas. Rio de Janeiro: Intrínseca, 2010.

TOCCHETTO, Fernanda Bordin. Uma construção possível sobre práticas e representações de grupos domésticos da Porto Alegre oitocentista. Revista de Arqueo- 
logia, n. 12-13, p. 55-71, 1999-2000.

TOCCHETTO, Fernanda Bordin. Fica dentro ou joga fora? Sobre práticas cotidianas na Porto Alegre moderna oitocentista. São Leopoldo: Oikos, 2010.

TOMÉ, Dyeinne Cristina. Modas e modos domésticos: os manuais de instrução feminina e a educação da mulher - Décadas de 1950 e 1960. Dissertação (Mestrado em Educação) - Universidade Estadual de Maringá, 2013.

WEISMANTEL, Mary. Obstinate things. In: VOSS, Barbara; CASELLA, Conlin (eds.) The archaeology of colonialism: intimate encounters and sexual effects. New York: Cambridge, 2011. 